ISSN 0103-9954

\title{
USO DO GEOPROCESSAMENTO NA IDENTIFICAÇÃO DE CONFLITO DE USO DA TERRA EM ÁREAS DE PRESERVAÇÃO PERMANENTE NA BACIA HIDROGRÁFICA DO RIO ALEGRE, ESPÍRITO SANTO
}

\author{
USE OF GEOPROCESSING IN LANDUSE CONFLICT INDENTIFICATION IN PERMANENT \\ PRESERVATION AREAS, ALEGRE RIVER WATERSHED, STATE OF ESPÍRITO SANTO, BRAZIL
}

\author{
Melchior Carlos do Nascimento ${ }^{1}$ Vicente Paulo Soares ${ }^{2}$ \\ Carlos Antônio Álvares Soares Ribeiro ${ }^{3}$ Elias Silva ${ }^{4}$
}

\begin{abstract}
RESUMO
Este estudo teve como objetivos elaborar um mapa de uso da terra com base nas imagens do satélite IKONOS II, delimitar de maneira automática as áreas de preservação permanente e identificar a ocorrência de conflito de uso, tendo como referência legal o Código florestal e a Resolução n. 303, do CONAMA. A pesquisa foi desenvolvida na bacia hidrográfica do rio Alegre, situada no sul do estado do Espírito Santo. Utilizando os recursos disponíveis no geoprocessamento, foi possível mapear 12 classes de uso da terra e delimitar as áreas de preservação permanente situadas no terço superior dos morros (49,7 ha); encostas com declividade superior a 45 graus $(27,5 \mathrm{ha})$; nascentes e suas respectivas áreas de contribuição (1.975,6 ha); margens dos cursos d'água com largura inferior a 10 metros (2.818,3 ha); e no terço superior das sub-bacias (4.695,8 ha), perfazendo um total de $9.566,9$ ha $(45,95 \%)$ da área total da bacia. A área de uso indevido correspondeu a $7.499,7$ ha $(43,80 \%)$, sendo as classes cafezal $(979,6$ ha) e pastagem $(6.179,8 \mathrm{ha})$ as principais ocorrências nessas áreas. Apenas $1.780,7$ ha $(18,61 \%)$ das áreas de preservação permanente estão protegidas por vegetação nativa.
\end{abstract}

Palavras-chaves: área de preservação permanente; geoprocessamento; uso da terra.

\begin{abstract}
The objective of this study map the landuse/landcover using IKONOS II data, automatize the delineation of permanent preservation areas and to identify landuse conflict based on the Brazilian Forest Code and Resolution $\mathrm{n}^{\circ} 303$ of CONAMA. The study was developed in the Alegre river watershed, located in the south region of the State of Espirito Santo, Brazil. Twelve landuse classes were mapped, along with the following permanent preservation areas: upper third of hills $(49,7 \mathrm{ha})$; hillsides with slopes above 45 degrees (27,5 ha); springs and their respective contributing areas (1.975,6 ha); riparian zones with width less than 10 meters (2.818,3 ha); and upper third of sub-basins (4.695,8 ha), summing 9.566,9 ha (45.95\%). The area of undue use corresponded to $7.499,7$ ha $(43,80 \%)$, with coffee plantation and pasture classes occupying most of this area $(74.73 \%)$. Only $1.780,7$ ha $(18.61 \%)$ of permanent preservation areas are protected by native vegetation $7.786,2$ ha $(81.39 \%)$.
\end{abstract}

Key words: permanent preservation area; geoprocessing; landuse.

\section{INTRODUÇÃO}

As conseqüências do desmatamento sobre os recursos hídricos têm repercutido na qualidade de vida das populações, afetando o equilíbrio ambiental das áreas drenadas pelas bacias hidrográficas. Embora a sua importância, para sobrevivência da humanidade, seja, sem dúvida, reconhecida pelos diferentes segmentos da sociedade, a medida que a demanda para os seus diversos usos (abastecimento, irrigação, geração de energia, entre outros) aumenta, as ações direcionadas para promover mudanças na forma predatória de sua utilização continuam sendo implementadas de maneira bastante limitada.

1. Geógrafo, Mestrando pelo Programa de Pós-Graduação em Engenharia Florestal, Departamento de Engenharia Florestal, Universidade Federal de Viçosa, CEP 36571-000, Viçosa (MG). mgeop@bol.com.br

2. Engenheiro Florestal, PhD., Professor do Departamento de Engenharia Florestal, Universidade Federal de Viçosa, CEP 36571-000, Viçosa (MG). vicente@ufv.br

3. Engenheiro Agrícola, PhD., Professor do Departamento de Engenharia Florestal, Universidade Federal de Viçosa, CEP 36571-000, Viçosa (MG). cribeiro@ufv.br

4. Engenheiro Florestal, Dr., Professor Adjunto do Departamento de Engenharia Florestal, Universidade Federal de Viçosa, CEP 36571-000, Viçosa (MG). eshamir@ufv.br

Recebido para publicação em 6/10/2004 e aceito em 10/06/2005. 
De maneira geral, os debates acerca da preservação e conservação da vegetação nativa, sobretudo aquela situada ao longo dos cursos d'água, nascentes e em regiões de topografia acidentada tem ocupado lugar de destaque, sendo um dos pilares para técnicos, pesquisadores e ambientalistas que preconizam a sua importância para proteção dos recursos hídricos. A função ambiental das áreas de preservação permanentes (APPs), definidas pelo Código Florestal brasileiro, tem sido justificada também por serem ambientes voltados para preservação da paisagem, do fluxo gênico da fauna e flora e por atuar como dissipador de energia erosiva (Brasil, 1965).

Apesar da legislação ambiental brasileira ser considerada bastante ampla, alguns fatores têm contribuído para torná-la pouco ágil (Crestana et al., 1993). Dentre esses, destaca-se a deficiência em meios e materiais para apurar com rigor as agressões ao meio ambiente. Diante desse fato, as metodologias possíveis de serem implementadas, por meio do geoprocessamento, tornam-se alternativas viáveis para reduzir de maneira significativa as deficiências relativas ao cumprimento das leis pertinentes. As condições oferecidas permitem integrar informação cartográfica e tabular, possibilitando por meio da análise ambiental estabelecer correlações espaciais, relações de causa e efeito e aspectos temporais que antes eram impraticáveis pelos meios tradicionais existentes (Townshend, 1992; Xavier-da-Silva, 1992), auxiliando de maneira decisiva a investigação da adequação do uso da terra em áreas de preservação permanente (Aulicino et al., 2000; Costa et al., 1996).

Outro aspecto relevante é que o uso dessa opção tecnológica adquire maior importância à medida que o problema a ser analisado apresenta-se em grandes dimensões, complexidade e com custos para operacionalização em campo bastante elevados (Pessoa et al., 1997). Nesse sentido, o monitoramento das áreas de preservação permanente tem sido um grande desafio sob o aspecto técnico e econômico, pois os critérios de delimitação com base na topografia exigem o envolvimento de pessoal especializado e de informações detalhadas da unidade espacial em análise. Entretanto, com o desenvolvimento de algoritmos e a sua incorporação ao conjunto de funções dos Sistemas de Informações Geográficas (SIG), tem sido possível o processamento rápido e eficiente dos dados necessários para caracterização das variáveis morfométricas do terreno (Oliveira, 2002), essenciais para análise das intervenções antrópicas em bacias hidrográficas.

A abordagem com base em produtos derivados a partindo desses algoritmos tem substituído, com vantagens, os métodos manuais tradicionalmente utilizados (Ribeiro et al., 2002), permitido a obtenção de resultados menos subjetivos, em menor tempo e replicáveis (Tribe, 1992) e apresentado níveis de exatidão comparáveis aos obtidos por métodos manuais (Garbrecht e Martz, 1993; Eash, 1994). A funcionalidade e eficácia desses procedimentos, integrada às informações produzidas pelas imagens de satélite, sobretudo, as de alta resolução espacial, podem produzir diagnósticos e fornecer subsídios capazes de identificar e mensurar a ocorrência de conflito de uso da terra em áreas de preservação permanente, fortalecendo as ações ambientais de monitoramento e como suporte para os instrumentos jurídicos de controle e físcalização desses ambientes.

Diversos trabalhos utilizando geotecnologias têm sido desenvolvidos com a finalidade de delimitar as APPs e identificar a ocorrência de conflito de uso da terra. Costa et al. (1996) identificaram categorias de APPs e elaboraram um diagnóstico qualitativo e quantitativo de uso da terra em uma área no município de Viçosa, Minas Gerais. Ainda nesse município, Soares et al. (2002) avaliaram as áreas de uso indevido da terra em uma microbacia por meio de restituidor fotográfico para determinação de APPs, e Oliveira (2002), por meio de geoprocessamento, conseguiu delimitar de maneira automática as APPs situadas nos topos do morro e em linhas de cumeada.

Sturm et al. (2004) analisaram a ocupação em APPs situadas na área urbana do município de Matinhos, PR por meio de imagens do sensor IKONOS II, usando o método de segmentação. Eles verificaram que após a classificação com o uso da lógica fuzzy, alguns objetos não foram corretamente classificados, sendo posteriormente editados de forma manual.

Este estudo teve como objetivo delimitar, de maneira automática, as áreas de preservação permanente com base nos critérios estabelecidos na Resolução n. 303, do CONAMA e no código florestal brasileiro, bem como identificar a ocorrência de conflito de uso da terra na bacia hidrográfica do rio Alegre, Espírito Santo. 


\section{MATERIAL E MÉTODOS}

\section{Aspectos físicos da área}

A bacia hidrográfica do rio Alegre está situada no município de Alegre, extremo sul do Espírito Santo, entre as latitudes $20^{\circ} 46^{\prime}$ e $20^{\circ} 55^{\prime}$ sul e longitudes $41^{\circ} 28^{\prime}$ e $41^{\circ} 37^{\prime}$ oeste de Greewinch. Com uma área de aproximadamente $208,2 \mathrm{~km} 2$, pertence à bacia hidrográfica do rio Itapemirim, sendo o seu curso d'água principal o rio Alegre (Figura 1).

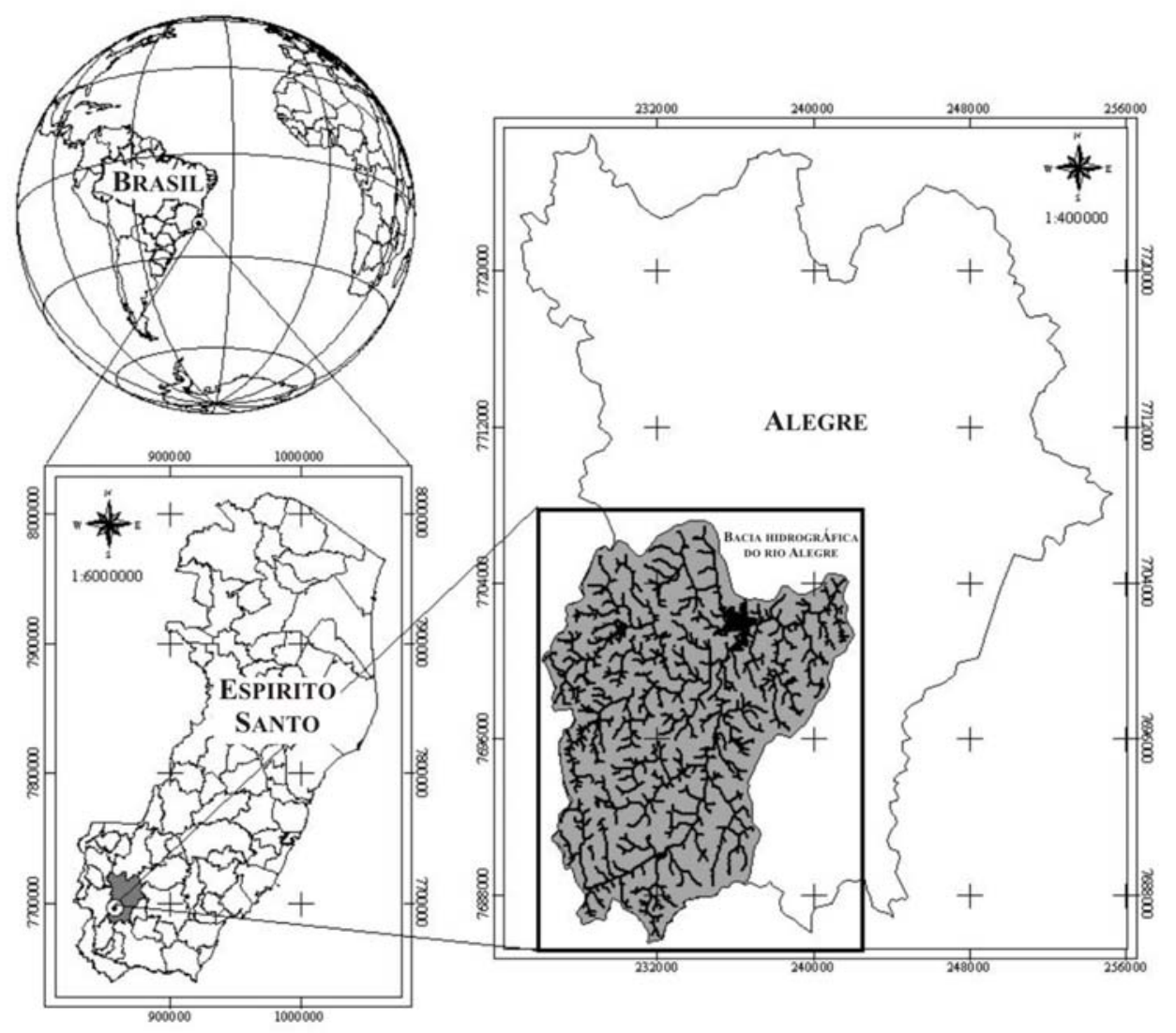

FIGURA 1: Localização da bacia hidrográfica do rio Alegre, estado do Espírito Santo.

FIGURE 1: Location of the Alegre river watershed, State of Espírito Santo, Brazil.

Segundo a classificação de Koppen, o clima da região é do tipo Cwa, caracterizado pelo inverno seco e o verão chuvoso. De maneira geral, a topografia da região possui relevo bastante acidentado, intercalada por reduzidas áreas planas. Na referida área, encontram-se basicamente culturas de subsistência, café e um grande predomínio de pastagens, além de remanescentes florestais nativos localizados sobretudo nos topos dos morros.

\section{Materiais utilizados}

Para a obtenção dos dados necessários à realização deste estudo, utilizou-se uma imagem digital do satélite IKONOS com resolução espacial de 4 metros, nos intervalos espectrais do visível $(0,52-0,69 \mu \mathrm{m})$ e infravermelho próximo $(0,76-0,90 \mu \mathrm{m})$, obtida em dezembro de 2002 ; as bases cartográficas planialtimétricas em formato digital na escala de 1:50.000, digitalizadas partindo das folhas SF-24-V-A-V-1, SF-24-V-A-IV-2, SF-24-V-A-V-3 e SF-24-V-A-IV-4 (IBGE, 1977), contendo as áreas urbanas, estradas, hidrografia, curvas de nível com eqüidistância de 20 metros e os pontos relativos às nascentes. $\mathrm{O}$ tratamento e análise dos dados foram realizados por meio dos softwares IDRISI 32, release II (Eastman, 1999) e ArcGIS, versão 8.2, módulos ArcMap e ArcInfo Workstation (ESRI, 2002). Além desses, foi utilizado 
também o Sistema de Posicionamento Global Diferencial (DGPS), modelo GTR, para coleta dos Pontos de Controle no Terreno (PCTs) usados na correção geométrica, e o Sistema Global de Posicionamento (GPS), modelo Garmim III Plus, para aferição das informações obtidas da classificação da imagem.

\section{Classificação visual da imagem}

Inicialmente, foram coletados Pontos de Controle Terrestres (PCTs) para o georreferenciamento da imagem, obtendo-se um RMSe (Root Mean Square Error) de 0,37 pixels. Em seguida, realizou-se a interpretação visual da imagem IKONOS, usando as bandas $2(0.52-0.60 \mu \mathrm{m}), 3(0.63-0.69 \mu \mathrm{m})$ e $4(0.76-$ $0.90 \mu \mathrm{m})$, seguida da digitalização das classes de uso da terra por meio do software IDRISI. Essa etapa se consistiu na distinção dos padrões tonais e das características feições da imagem, tais como tamanho, forma e textura. Posteriormente, foram realizadas visitas a campo objetivando identificar a fidedignidade das categorias de uso da terra geradas na classificação preliminar e também para eliminar possíveis dúvidas. Essa etapa se consistiu na seleção de 30 pontos de controle na imagem IKONOS, os quais foram checados no campo. De posse dessas informações, foi possível chegar a classificação final do uso da terra. Com a finalidade de verificar a confiabilidade do mapa gerado, foi realizada uma avaliação da exatidão por meio do índice Kappa, conforme a equação a seguir:

$$
\hat{\mathrm{K}}=\frac{\mathrm{N} \sum_{i=1}^{r} x_{i i}-\sum_{i=1}^{r}\left(x_{i}+* x+i\right)}{\mathrm{N}^{2}-\sum_{i=1}^{r}\left(x_{i}+* x+i\right)}
$$

Em que: $\hat{\mathrm{K}}$ = Índice de concordância Kappa; $\mathrm{r}$ = número de linhas na matriz; xii = número de observações na linha[i] e coluna[i]; $\mathrm{xi}+\mathrm{e} \mathrm{x}+\mathrm{i}=$ totais marginais da linha[i] e coluna[i], respectivamente; e $\mathrm{N}=$ número total de observações.

\section{Delimitação das áreas de preservação permanente (APPs) com base na resolução n. 303 CONAMA}

Foi adotada a medotologia desenvolvida por Ribeiro et al. (2002) para a delimitação automática das áreas de preservação permanente, implementada tomando por base modelo digital de elevação hidrologicamente consistente. Assim, valendo-se das visitas a campo realizadas durante o período de execução desse trabalho, identificaram-se, conforme itens dos art. $2^{\circ}$ e $3^{\circ}$, da Resolução n. 303 do CONAMA, as categorias de APPs situadas no terço superior dos morros (APP-1), nas encostas com declividade superior a 45 graus (APP-2), nas nascentes e suas áreas de contribuição (APP-3), margens dos cursos d'água (APP-4) e terço superior das sub-bacias (APP-5).

\section{Desenvolvimento do Modelo Digital Hidrologicamente Consistente (MDHEC)}

Os dados utilizados para geração do MDEHC foram as curvas de nível e a rede hidrográfica, ambas na escala de 1:50.000, além do valor referência de exatidão cartográfica de 0,2 mm (Moura, 1997), adotado nesse estudo apenas para calcular a resolução espacial das células do MDHEC. Assim, para determinar a menor dimensão no terreno representada no mapa, isto é, a resolução espacial, multiplicou-se a exatidão cartográfica pelo fator de escala, que correspondeu a 10 metros.

Determinada a dimensão da célula de saída e de posse dos referidos dados, a geração do MDHEC da bacia hidrográfica do rio Alegre foi realizada utilizando o algoritmo de interpolação TOPOGRID, disponível no comando Grid tools do módulo ArcInfo Workstation. As operações necessárias para geração do MDHEC, por meio desse algoritmo, exigiram a orientação dos arcos da rede hidrográfica no sentido do escoamento e o ajuste da altimetria à hidrografia.

Em seguida, foram realizadas operações de pós-processamento com a finalidade de identificar e eliminar a ocorrência de imperfeições (depressões espúrias) no MDHEC e para criação de uma calha ao longo da rede hidrográfica, objetivando garantir a convergência do escoamento superficial até a foz da hidrografia. De acordo com Tribe (1992) e Garcia e Camarasa (1999), essas imperfeições são muito freqüentes nos MDEs e derivam-se de erros presentes nos dados de entrada ou introduzidos no processo de interpolação. As falsas depressões constituem um problema importante na geração de modelos de predição do escoamento, pois interrompem o escoamento superficial. Devem ser removidas, portanto, para se ter um MDE consistente sob o ponto de vista hidrológico. Para o preenchimento dessas imperfeições, utilizou-se o 
comando FILL, disponível na opção Grid tools do software ArcInfo Workstation.

\section{Delimitação das APPs ao redor das nascentes e ao longo dos cursos d'água}

Nessa etapa, foram utilizadas as bases de dados correspondentes ao MDEHC, aos pontos relacionados às nascentes e à rede hidrográfica orientada no sentido da foz. A delimitação das áreas de preservação no entorno das nascentes (APP-3) e das faixas ao longo dos cursos d'água (APP-4), conforme itens dos art. $2^{\circ}$ e $3^{\circ}$, da Resolução n. 303 do CONAMA foi realizada por meio do comando Create Buffer. A categoria APP-4 foi delimitada com faixas de 30 metros para ambas as margens dos cursos d'águas com largura inferior a 10 metros. A APP-3 foi obtida delimitando-se um raio de 50 metros no entorno das nascentes, superpondo-o às respectivas áreas de contribuição.

\section{Delimitação das APPs em topos de morros}

Seguindo a metodologia descrita por Ribeiro et al. (2002) foi realizada a inversão da direção do escoamento do MDHEC por meio da reclassificação dos valores que representam a direção de escoamento (Figura 2); e eliminadas as células da hidrografia objetivando garantir que as depressões situadas sobre estas não fossem identificadas.

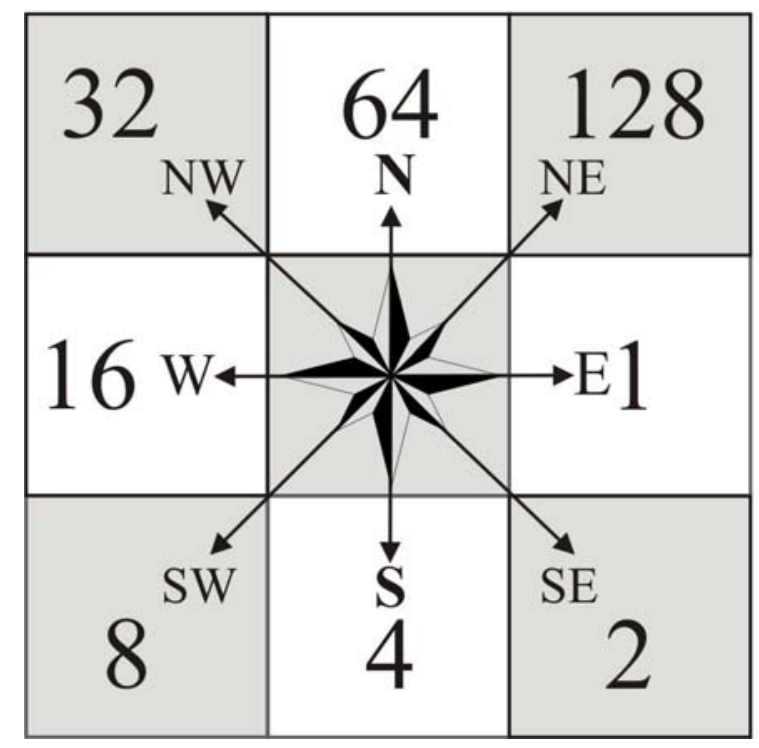

\begin{tabular}{|c|c|}
\hline Origem & Reclass. \\
1 & 16 \\
2 & 32 \\
4 & 64 \\
8 & 128 \\
16 & 1 \\
32 & 2 \\
64 & 4 \\
128 & 8 \\
\hline
\end{tabular}

FIGURA 2: Reclassificação dos valores da direção de escoamento.

FIGURE 2: Reclassification of the flowing direction values.

Considerando a direção de escoamento invertida, foram identificados os topos de morro como sendo as depressões, sendo excluídas as células que representavam as linhas de cumeada. Esse procedimento objetivou garantir que as depressões localizadas sobre as linhas de cumeada não fossem identificadas como topos de morro.

A seguir, foi identificada a base do morro, que correspondeu à área de contribuição drenada por uma depressão. Determinaram-se, então, as altitudes da base e do topo do morro por meio das identificações, respectivamente, do menor e maior valor de altitude das células do MDHEC que representam o morro. Com isso, foi possível determinar a altura do morro pela diferença entre a altitude do topo do morro e a altitude da sua base.

Finalizando, foram selecionados os morros com altitude entre $50 \mathrm{~m}$ e $300 \mathrm{~m}$ e com declividade majoritariamente superior a 30\%. Para delimitar as áreas de preservação situadas apenas nos topos do morros, calculou-se a relação entre a altura e a altura do topo do morro em relação à base para cada célula do MDHEC. Esse procedimento objetivou identificar todas as células que possuíam relação igual ou superior a 2/3, correspondendo a APP-2. 


\section{Delimitação das APPs em linhas de cumeada}

De acordo com a Resolução n. 303, do CONAMA, essa categoria de APP está compreendida apenas ao longo das linhas de cumeada com altitude mínima de $50 \mathrm{~m}$. Portanto, calculou-se para cada célula do MDEHC a relação entre a sua altura e a altura do topo em relação à base. A delimitação das áreas de preservação ao longo das linhas de cumeada (terço superior dos morros - APP-1 e terço superior das subbacias - APP-5) consistiu na identificação das células que apresentaram relação igual ou superior a $2 / 3$ (Ribeiro et al. 2002).

\section{Análises de conflito de uso da terra}

$\mathrm{Na}$ identificação e análise do conflito de uso nas áreas destinadas à preservação permanente foram utilizados os mapas temáticos de uso e ocupação da terra e das categorias de APPs. Inicialmente, realizou-se a sobreposição desses mapas por meio dos procedimentos disponíveis no módulo de análise do ArcMap (Geoprocessing Wizard). Em seguida, as ocorrências de conflito de acordo com as classes de uso foram identificadas e devidamente mensuradas, executando as funções de busca (Query Build) e de cálculo de área.

\section{RESULTADOS E DISCUSSÕES}

\section{Classes de uso da terra}

A imagem do satélite IKONOS, bandas 2, 3 e 4, obtida em dezembro de 2002, e os levantamentos de campo permitiram identificar e mapear 12 classes de uso da terra, destacando-se 475 fragmentos florestais (Figura 3).

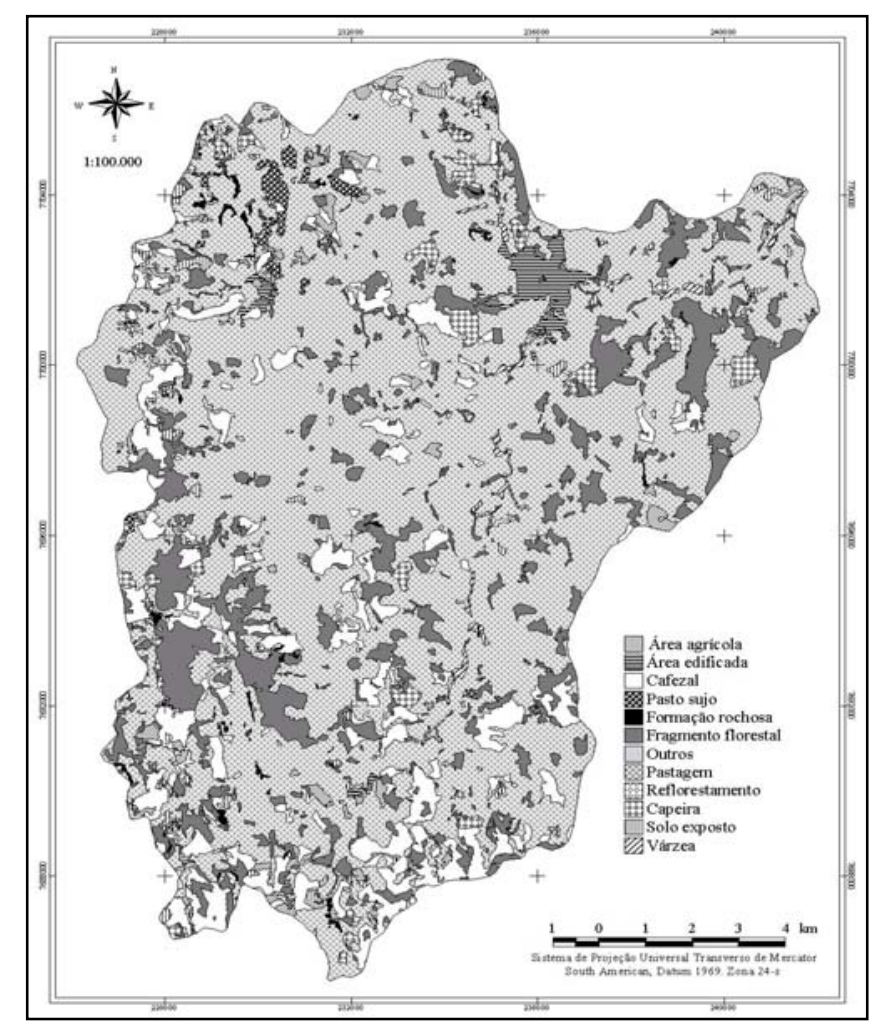

FIGURA 3: Classes de uso da terra da bacia hidrográfica do rio Alegre, Espírito Santo.

FIGURE 3: Landuse classes in the Alegre river watershed, State of Espirito Santo, Brazil.

O mapa representado pela Figura 3 teve a sua acurácia verificada pela matriz de erros, usando o índice de concordância Kappa, que considera a proporção de amostras corretamente classificadas correspondentes à razão entre a soma da diagonal principal da matriz de erros (amostras corretamente classificadas) e a soma de todos os elementos desta matriz (número total da amostra) tendo como referência o número total de classes (Cohen, 1960, citado por Rosenfield \& Fitzpatrick-Lins, 1986). Assim, o resultado obtido com a utilização do estimador de acerto Kappa (matriz de erros) para a classificação realizada, foi de 
0,85, valor considerado excelente $(0,8<\mathrm{K} \leq 1)$ (Foody, 1992; Congalton \& Green, 1998), indicando que a classificação alcançou um resultado satisfatório.

Com relação às classes mapeadas, a análise do Tabela 1 mostra que a pastagem e os fragmentos florestais foram as classes de maiores ocorrências na área, com 14.130,1 e 2.979,9 ha respectivamente. Por outro lado, reflorestamento $(17,0 \mathrm{ha})$ e a classe denominada como outros $(9,8 \mathrm{ha})$ apresentaram as menores contribuições na composição da paisagem.

TABELA 1: Classes de uso da terra mapeadas na imagem do satélite IKONOS na bacia hidrográfica do rio Alegre, Espírito Santo.

TABLE 1: Landuse classes mapped on the IKONOS image, Alegre river watershed, State of Espírito Santo, Brazil.

\begin{tabular}{rl|rr|rr}
\hline \multirow{2}{*}{ N. } & \multicolumn{2}{|c|}{$\begin{array}{c}\text { Classe de uso } \\
\text { e ocupação }\end{array}$} & \multicolumn{2}{c|}{ Área } & \multicolumn{2}{c}{ Perímetro } \\
\cline { 3 - 6 } & (ha) & $(\%)$ & $(\mathrm{m})$ & $(\%)$ \\
\hline 7 & Pastagem & $14.130,1$ & 67,87 & $947.726,5$ & 41,66 \\
6 & Fragmento florestal & $2.979,9$ & 14,31 & $591.042,8$ & 25,98 \\
3 & Cafezal & $2.086,2$ & 10,02 & $319.988,4$ & 14,07 \\
4 & Capoeira & 385,8 & 1,85 & $63.135,4$ & 2,78 \\
10 & Solo exposto & 314,9 & 1,51 & $117.624,9$ & 5,17 \\
1 & Área agrícola & 312,9 & 1,50 & $75.418,7$ & 3,32 \\
2 & Área edificada & 253,3 & 1,22 & $34.494,0$ & 1,52 \\
8 & Pasto sujo & 135,4 & 0,65 & $23.304,1$ & 1,02 \\
11 & Várzea & 112,0 & 0,54 & $39.051,9$ & 1,72 \\
5 & Formação rochosa & 83,4 & 0,40 & $47.158,4$ & 2,07 \\
9 & Reflorestamento & 17,0 & 0,08 & $8.158,8$ & 0,36 \\
12 & Outros & 9,8 & 0,05 & $7.714,9$ & 0,34 \\
\hline Total & & $20.819,8$ & 100,00 & $2.274 .818,8$ & 100,00 \\
\hline
\end{tabular}

Considerando as atividades agropecuárias como uma das principais responsáveis pela transformação da paisagem natural, constatou-se que as classes cafezal $(10,02 \%)$, área agrícola $(1,50 \%)$, reflorestamento $(0,08 \%)$ e pastagem $(67,86 \%)$ corresponderam a $80,21 \%$ da área. A expressiva participação dessas classes na composição da paisagem demonstra os intensos processos de antropização a que a área tem sido submetida. Vale ressaltar que, em conseqüência de sua importância para economia da região, procurou-se distinguir visualmente a classe cafezal da área agrícola, caracterizada assim pela indefinição na distinção dos padrões espectrais da imagem e na consulta realizada durante a verificação de campo.

\section{Áreas de preservação permanente}

A metodologia de delimitação automática das áreas de preservação permanente (APPs) tendo como referência legal a Resolução n. 303, do CONAMA, possibilitou identificar e quantificar as categorias de APPs situadas no terço superior dos morros - APP-1, nas encostas com declividade superior a 45 graus APP-2, nas nascentes e suas respectivas áreas de contribuição - APP-3, ao longo das margens cursos d'águas - APP-4 e no terço superior das sub-bacias - APP-5, conforme Figura 4.

A análise da Tabela 2 mostra que a menor e a maior participação entre as categorias de APPs correspondeu às APP-2 e APP-5, com 27,5 ha $(0,29 \%)$ e 4.695,8 ha $(49,08 \%)$ respectivamente. Nota-se ainda que as APPs ocuparam uma área de 9.566,9 ha, de um total de 20.819,8 ha da área da bacia, representando $45,95 \%$ de áreas legalmente protegidas. Oliveira (2002) desenvolveu estudo semelhante, na microbacia do Paraíso, município de Viçosa, MG, que apresenta características topográficas parecidas, identificando $52,13 \%$ da área como áreas de preservação permanente. De acordo com esse autor, a área das APPs delimitadas pelo processo automático foi aproximadamente $20 \%$ maior que a obtida pelo processo manual. 


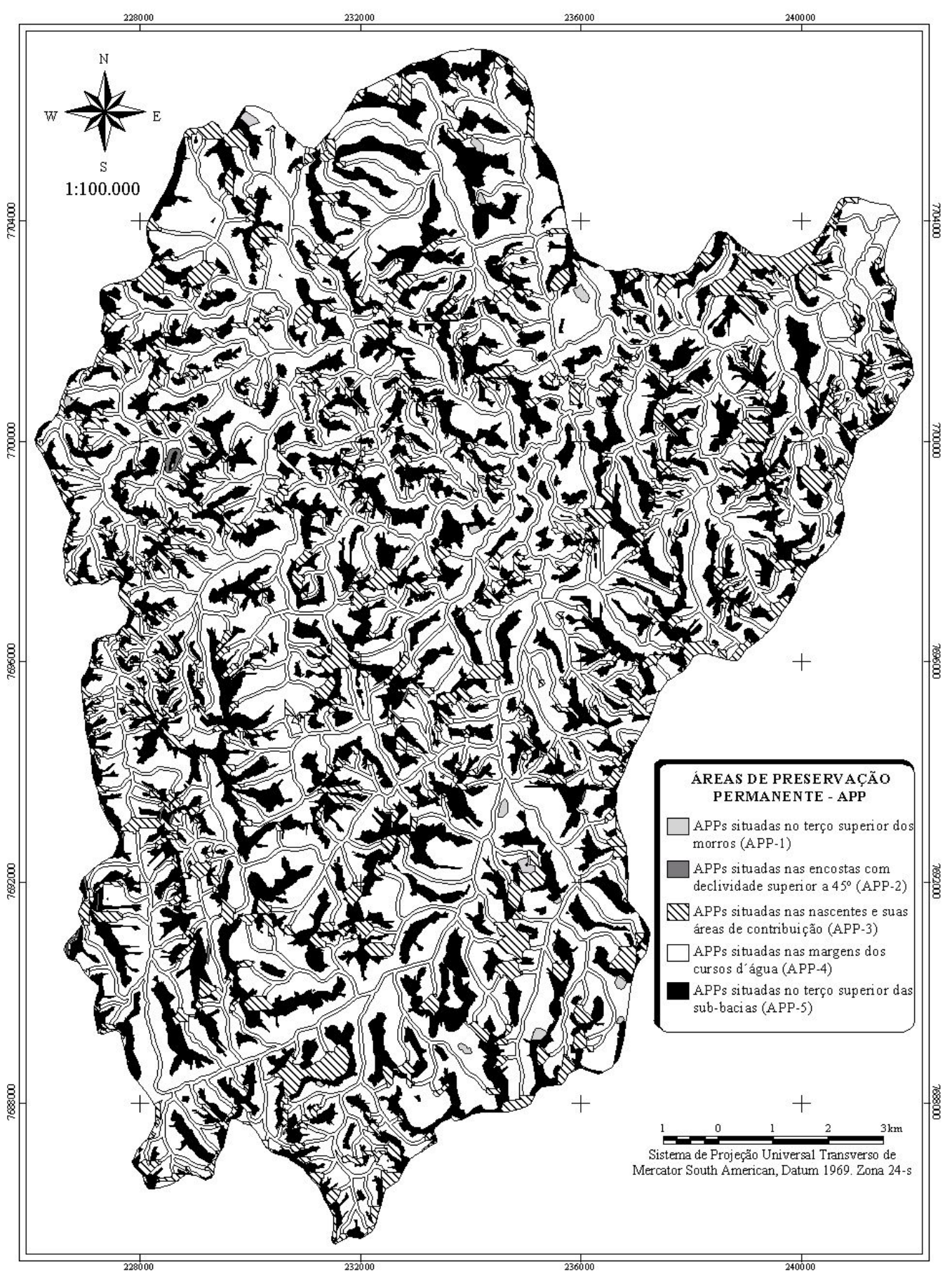

FIGURA 4: Categorias de APPs mapeadas na bacia hidrográfica do rio Alegre, Espírito Santo, Brasil. FIGURE 4: Categories APPs mapped in the Alegre river watershed, State of Espírito Santo, Brazil. 
TABELA 2: Quantificação das APPs mapeadas na bacia hidrográfica do rio Alegre, Espírito Santo.

TABLE 2: Quantification of the APPs mapped in the Alegre river watershed, State of Espírito Santo, Brazil.

\begin{tabular}{l|c|c|c}
\hline \multirow{2}{*}{ Descrição das categorias de APPs } & Categorias de & \multicolumn{2}{c}{ Área } \\
\cline { 3 - 4 } & APPS & $($ ha $)$ & \multicolumn{1}{c}{$(\%)$} \\
\hline Terço superior dos morros & APP-1 & 49,7 & 0,52 \\
Encostas com declividade superior a 45 & APP-2 & 27,5 & 0,29 \\
Nascentes e suas áreas de contribuição & APP-3 & $1.975,6$ & 20,65 \\
Margens dos cursos d'água & APP-4 & $2.818,3$ & 29,46 \\
Terço superior das sub-bacias & APP-5 & $4.695,8$ & 49,08 \\
\hline Total & & $9.566,9$ & 100,00 \\
\hline
\end{tabular}

Pela análise da Figura 5, nota-se que dos $45,95 \%$ de áreas legalmente protegidas, 22,55\% consistiram nas categorias de APPs situadas no terço superior das sub-bacias (APP-5), 13,54\% nas margens dos cursos d'água (APP-4), 9,49\% nas nascentes e suas respectivas áreas de contribuição (APP3) e apenas 0,37\% correspondeu às demais categorias (APP-1 e APP2). Embora essas categorias correspondam a 45,95\% da área total da bacia hidrográfica do rio Alegre, apenas 18,61\% (1.780,7 ha) estão efetivamente protegidas, sendo constituídas por fragmentos florestais.

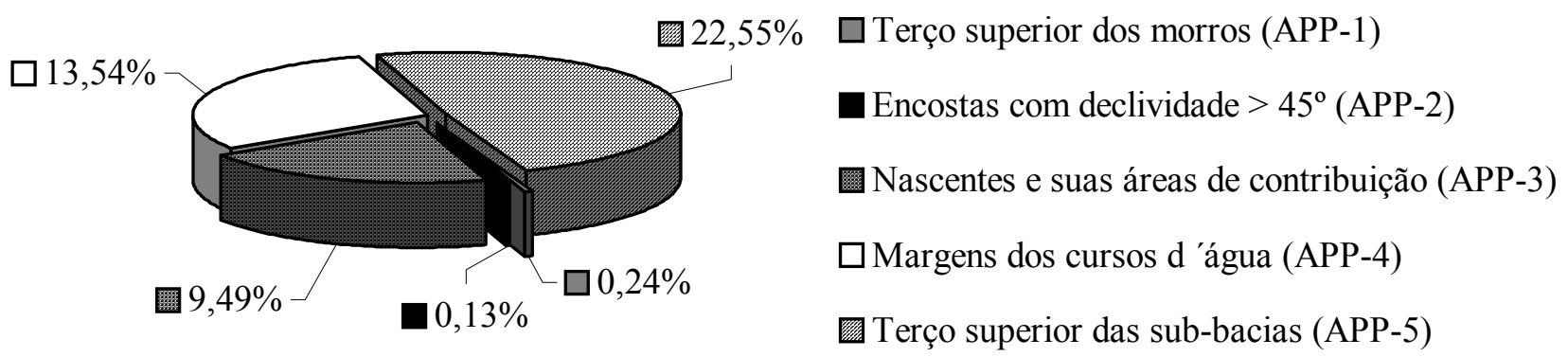

FIGURA 5: Quantificação das categorias de APPs na bacia hidrográfica do rio Alegre, Espírito Santo.

FIGURE 5: Quantification the of APPs categories in Alegre river watershed, State of Espírito Santo, Brazil.

Analisando a Figura 6, verifica-se que do total de 1.780,7 ha referentes as áreas efetivamente protegidas por fragmentos florestais, $1.055,1$ ha $(59,25 \%)$ correspondem ao terço superior das sub-bacias (APP-5), 452,2 ha (25,39\%) às nascentes e suas respectivas áreas de contribuição (APP-3), 255,0 ha $(14,32 \%)$ as margens dos cursos d'água (APP-4), 10,0 ha (0,56\%) às encostas com declividade superior a 45 graus (APP-2) e apenas 8,4 ha $(0,47 \%)$ ao terço superior dos morros (APP-1).

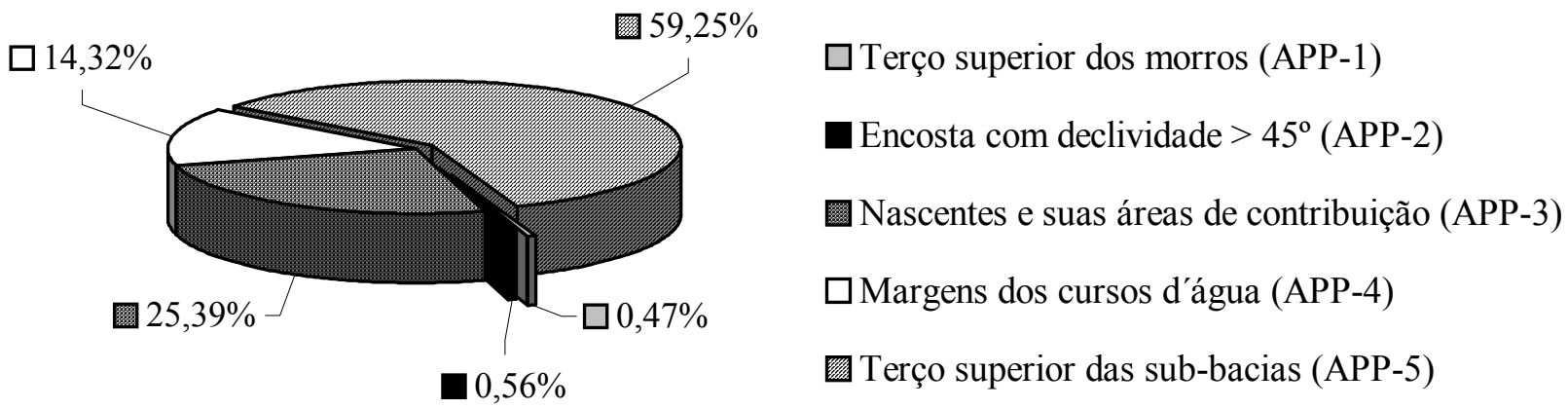

FIGURA 6: Quantificação da ocorrência das categorias de APPs entre os fragmentos florestais mapeados da bacia hidrográfica do rio Alegre, Espírito Santo, Brasil.

FIGURE 6: Quantification of the occurrence APPs categories fragment forest mapped of the Alegre river watershed, State of Espírito Santo, Brazil. 


\section{Conflito de uso da terra}

De maneira geral, as classes de uso da terra mapeadas estão parcialmente situadas nas áreas legalmente protegidas, sobretudo aquelas resultantes de ações antrópicas. Contudo, apenas as classes pertencentes ao sistema antrópico caracterizam o conflito de uso, pois resultam da intervenção humana. Do total de $9.566,9$ ha relativos às APPs, 7.749,9 ha (78,39\%) estão sendo afetados por uso indevido, 286,5 ha $(2,99 \%)$ são ocupadas pelas classes pertencentes ao sistema fitosionômico natural e apenas $1.780,7$ ha $(18,61 \%)$ estão cobertas por fragmentos florestais nativos.

A análise da Tabela 3 mostra que as classes cafezal e pastagem ocuparam a maior parte das APPs, com 979,6 ha $(10,24 \%)$ e $6.169,8$ ha $(64,49 \%)$, respectivamente. As áreas de APPs situadas nas margens de cursos d'água (APP-4) e no terço superior das sub-bacias (APP5), com 217,0 ha 2.860,0 ha, respectivamente, foram as categorias mais afetadas por essas classes de uso da terra. Por outro lado, observou-se que as áreas ocupadas pelas classes caracterizadas como sistemas fitosionômicos naturais ocorreram apenas em 2,99 \% das categorias de APPs, sendo capoeira (173,3 ha) e pasto sujo (42,3 ha) as principais responsáveis. Com relação aos fragmentos florestais, mais uma vez, vale ressaltar que estes representam áreas efetivamente preservadas com cobertura vegetal nativa.

TABELA 3: Quantificação da ocorrência de conflito de uso da terra nas categorias de APPs delimitadas na bacia hidrográfica do rio Alegre, Espírito Santo, Brasil.

TABLE 3: Quantification of the conflict occurrence landuse in APPs categories mapped in the Alegre river watershed, State of Espírito Santo, Brazil.

\begin{tabular}{|c|c|c|c|c|c|c|c|c|}
\hline \multirow{2}{*}{\multicolumn{2}{|c|}{ Classes uso da terra }} & \multicolumn{5}{|c|}{$\begin{array}{c}\text { Categorias de APPs } \\
\text { Área (ha) }\end{array}$} & \multicolumn{2}{|c|}{$\begin{array}{l}\text { Total } \\
\text { Área }\end{array}$} \\
\hline & & APP-1 & APP-2 & APP-3 & APP-4 & APP-5 & (ha) & $(\%)$ \\
\hline \multirow{7}{*}{ 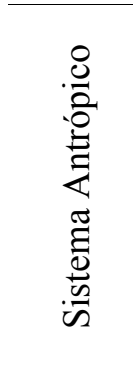 } & Área agrícola & & 0,1 & 38,6 & 38,8 & 61,0 & 138,5 & 1,45 \\
\hline & Área edificada & 0,5 & & 6,6 & 47,3 & 15,6 & 70,0 & 0,73 \\
\hline & Cafezal & 2,2 & 1,8 & 218,1 & 217,0 & 540,5 & 979,6 & 10,24 \\
\hline & Outros & & & 0,5 & 3,0 & 0,04 & 3,5 & 0,04 \\
\hline & Pastagem & 34,0 & 15,5 & 1182,9 & 2077,3 & 2860,0 & $6.169,8$ & 64,49 \\
\hline & Reflorestamento & & & 1,5 & 1,8 & 3,3 & 6,6 & 0,07 \\
\hline & Solo exposto & & & 23,2 & 54,8 & 53,8 & 131,8 & 1,38 \\
\hline \multirow{5}{*}{ 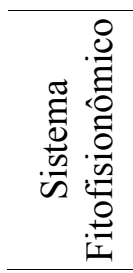 } & Fragmentos florestais* & 8,4 & 10,0 & 452,2 & 255,0 & 1055,1 & $1.780,7$ & 18,61 \\
\hline & Pasto sujo & 0,5 & & 9,9 & 9,5 & 22,4 & 42,3 & 0,44 \\
\hline & Formação rochosa & & & 4,8 & 20,5 & 12,8 & 38,1 & 0,40 \\
\hline & Capoeira & 4,0 & 0,02 & 37,3 & 62,6 & 69,3 & 173,3 & 1,81 \\
\hline & Várzea & & 0,1 & 0,03 & 30,7 & 1,9 & 32,8 & 0,34 \\
\hline Total & & 49,7 & 27,5 & $1.975,6$ & $2.818,3$ & $4.695,8$ & $9.566,9$ & 100,00 \\
\hline
\end{tabular}

Em que: * a áreas de preservação permanentes protegidas por formação florestal nativa.

Ainda na Tabela 3, verificou-se que as classes regeneração e várzea, com 0,02 ha e 0,03 ha, respectivamente, ocuparam as menores porções entre as categorias de APPs mapeadas. Além disso, verificou-se que as áreas de preservação permanentes situadas nas margens dos cursos d'água (APP-4) apresentaram, dentre as categorias de APPs, a maior redução em área de floresta nativa, com 2.563,3 ha (90,95\%) ocupados por alguma classe de uso da terra e apenas 255,0 ha $(9,05 \%)$ efetivamente cobertos por fragmentos florestais.

A análise da Figura 7 mostra, em termos percentuais, que as categorias de APPs menos afetadas pelas classes de uso da terra e, por conseqüência, com maiores áreas cobertas por fragmentos florestais, foram as APPs situadas nas encostas com declividade superior a 45 graus (APP-2) e nas nascentes e suas respectivas áreas de contribuição (APP-3), com 63,62 e 77,11\% respectivamente. 


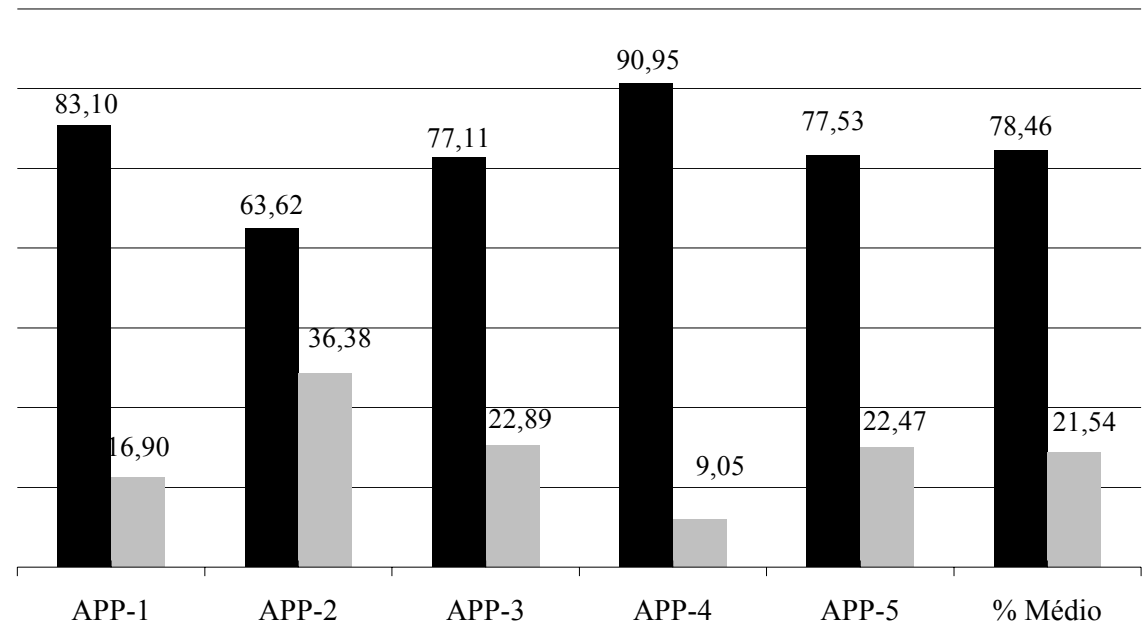

Classe de uso da terra

Fragmento fl

FIGURA 7: Percentual total do tipo de cobertura entre as categorias de APPs mapeadas.

FIGURE 7: Total percentage of vegetation cover between mapped APPs categories.

O conflito de uso na bacia hidrográfica do rio Alegre encontra-se em um estado bastante acentuado, com 78,46\% das atividades antrópicas sendo desenvolvidas nas áreas legalmente protegidas pela legislação ambiental. Analisando a Tabela 4, nota-se que o uso indevido entre as classes resultantes de ações

TABELA 4: Quantificação das áreas ocupadas pelas classes de uso da terra em observância à legislação ambiental na bacia hidrográfica do rio Alegre, Espírito Santo, Brasil.

TABLE 4: Quantification of the occupied area by landuse classes in agreement to environmental legislation in the Alegre river watershed, State of Espirito Santo, Brazil.

\begin{tabular}{|c|c|c|c|c|c|c|}
\hline & \multirow{3}{*}{ Sistema antrópico } & \multicolumn{5}{|c|}{ Ocorrência } \\
\hline & & \multicolumn{2}{|c|}{ Uso devido } & \multicolumn{2}{|c|}{ Uso indevido } & \multirow{2}{*}{$\begin{array}{c}\text { Total } \\
\text { (ha) } \\
\end{array}$} \\
\hline & & (ha) & $(\%)$ & (ha) & $(\%)$ & \\
\hline \multirow{9}{*}{ 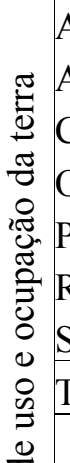 } & Área agrícola & 174,4 & 55,75 & 138,5 & 44,25 & 312,9 \\
\hline & Área edificada & 183,3 & 72,36 & 70,0 & 27,64 & 253,3 \\
\hline & Cafezal & $1.106,6$ & 53,05 & 979,6 & 46,95 & $2.086,2$ \\
\hline & Outros & 6,3 & 64,37 & 3,5 & 35,63 & 9,8 \\
\hline & Pastagem & $7.960,3$ & 56,34 & $6.169,8$ & 43,66 & $14.130,1$ \\
\hline & Reflorestamento & 10,5 & 61,35 & 6,6 & 38,65 & 17,0 \\
\hline & Solo exposto & 183,1 & 58,14 & 131,8 & 41,86 & 314,9 \\
\hline & Total & $9.624,5$ & 56,20 & $7.499,7$ & 43,80 & $17.124,2$ \\
\hline & \multirow{3}{*}{ Sistema fitofiosionômico } & \multicolumn{5}{|c|}{ Ocorrência } \\
\hline i & & \multicolumn{2}{|c|}{ Outras áreas } & \multicolumn{2}{|c|}{ Categorias de APPs } & Total \\
\hline 岕 & & (ha) & $(\%)$ & (ha) & $(\%)$ & (ha) \\
\hline U & Pasto sujo & 93,0 & 68,74 & 42,3 & 31,26 & 135,4 \\
\hline & Formação rochosa & 45,4 & 54,37 & 38,1 & 45,63 & 83,4 \\
\hline & Capoeira & 212,5 & 55,08 & 173,3 & 44,92 & 385,8 \\
\hline & Várzea & 79,3 & 70,76 & 32,8 & 29,24 & 112,0 \\
\hline & Total & 430,2 & 60,03 & 286,5 & 39,97 & 716,6 \\
\hline
\end{tabular}


antrópicas perfazem um total de $7.499,7$ ha $(43,80 \%)$. Do total de $14.130,1$ ha mapeados como pastagem, $6.169,8$ ha (43,66\%) ocorreram em APPs e 7.960,3 ha (56,34\%) ocuparam as áreas legalmente. Embora essa classe tenha ocupado a maior parte das categorias de APPs, a classe cafezal apresentou relativamente a maior ocorrência de uso indevido, com 979,6 ha (46,95\%).

Por outro lado, as classes caracterizadas como sistema fitosionômico ocuparam 286,5 ha das categorias de APPs. Desse total, 173,3 ha estão cobertos pela classe capoeira, que corresponde às áreas com cobertura florestal em estágio de regeneração. A Figura 8 mostra a participação das classes de uso da terra na bacia hidrográfica do rio Alegre.

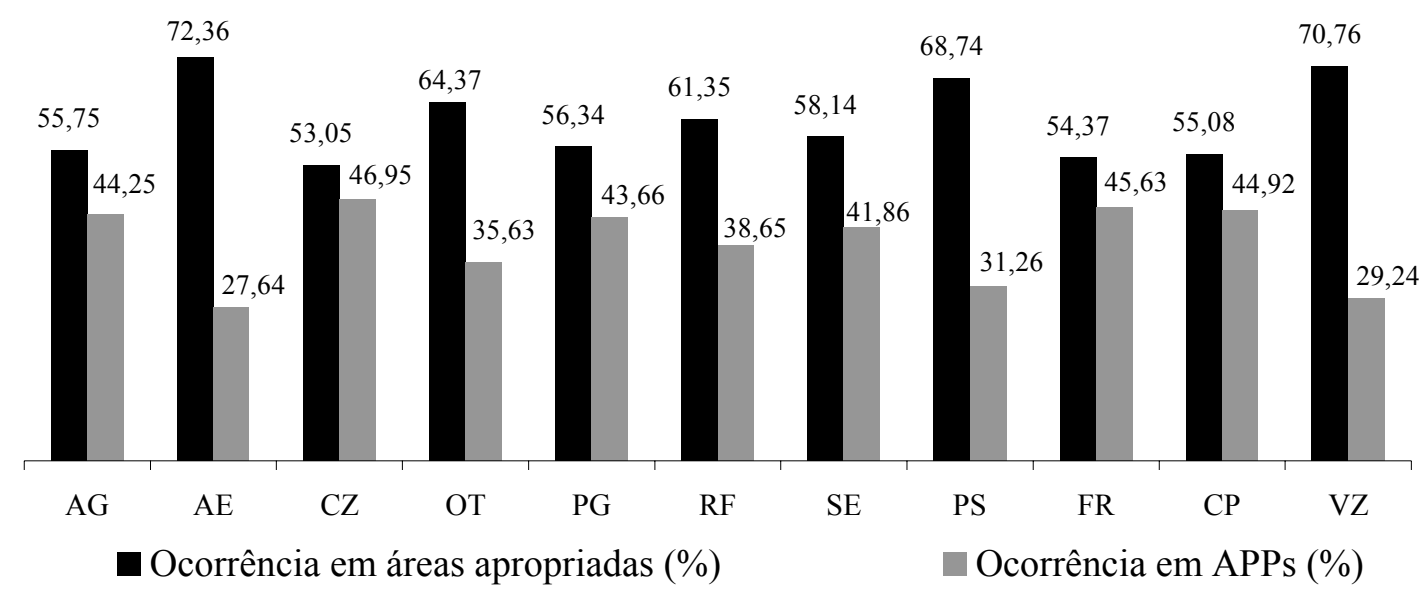

FIGURA 8: Percentual de ocorrência das classes de uso da terra na bacia hidrográfica do rio Alegre, Espírito Santo, Brasil.

FIGURE 8: Percentage occurrence of landuse classes in the Alegre river watershed, State of Espírito Santo, Brazil.

\section{CONCLUSÕES}

O presente estudo teve como finalidade elaborar um mapa de uso da terra e identificar a ocorrência de conflito na bacia hidrográfica do rio Alegre, com base na Resolução n. 303 do CONAMA, utilizando técnicas de geoprocessamento. Com base nos resultados obtidos, foi possível concluir que:

A adoção do SIG permitiu a delimitação automática das áreas de preservação permanentes e identificação de conflito de uso das classes presentes na área de estudo.

A utilização da imagem de alta resolução espacial (IKONOS) permitiu a elaboração do mapeamento valendo-se da classificação visual e verificações de campo, de 12 classes de uso da terra.

A área total da bacia hidrográfica do rio Alegre é de 20.819,8 ha, dos quais $67,87 \%$ são cobertos por pastagem, $14,31 \%$ por fragmentos florestais e $10,02 \%$ por cafezal.

A metodologia de delimitação automática das Áreas de Preservação Permanente (APPs) mostrou-se bastante eficiente, produzindo de maneira automatizada informações precisas sobre as suas dimensões e distribuição espacial na paisagem.

As categorias de áreas de preservação permanentes situadas nas margens dos cursos d'água, encostas com declividade superior a 45 graus, áreas de contribuição das nascentes, terço superior do morro, e terço superior das sub-bacias ocuparam 9.566,9 ha $(45,95 \%)$ da área total da bacia hidrográfica do rio Alegre. Dentre essas, a maior participação correspondeu às APPs situadas no terço superior das sub-bacias, com $4.695,8$ ha $(49,08 \%)$ e a menor nas áreas relacionadas às encostas com declividade superior a 45 graus, com apenas 27,5 ha $(0,29 \%)$.

Em se tratando do conflito de uso da terra, as classes cafezal $(979,6$ ha) e pastagem (6.169,8 ha) foram as de maior ocorrência, ocupando, respectivamente, 10,24 e 64,49\% das áreas legalmente protegidas 
pela legislação ambiental. Em contrapartida, a classe de área edificada $(70,0$ ha) apresentou a menor ocorrência de uso indevido, com 27,64\%.

\section{AGRADECIMENTO}

À equipe do Núcleo de Estudos e Difusão Tecnológica (NEDTEC), pelo importante apoio e suporte na coleta dos dados de campo, bem como por ter disponibilizado a imagem IKONOS.

\section{REFERÊNCIAS BIBLIOGRÁFICAS}

AULICINO, L.C.M; RUDORFF, B.F.T; MOREIRA, M.A; MEDEIROS, J.S; SIMI JÚNIOR, R. Subsídios para o Manejo Sustentável da Bacia Hidrográfica do Rio Una através do uso de técnicas de Geoprocessamento e Sensoriamento Remoto. In: SIMPÓSIO LATINO AMERICANO DE PERCEPCIÓN REMOTA, 9., 2000, Puerto Iguazu, Missiones, Argentina. Anais... Argentina, 2000.

BRASIL. Lei Federal n. 4.771. Institui o Novo Código Florestal Brasileiro de 15 de setembro de 1965.

CONGALTON, R. G.; GREEN, K. Assessing the accuracy of remotely sensed data: Principles and Practices. New York: Lewis Publishers, 1998. 137p.

COSTA, T. C. C., SOUZA, M. G., BRITES, R. S. Delimitação e caracterização de áreas de preservação permanente por meio de um Sistema de Informações Geográficas (SIG). Revista Árvore.Viçosa - MG, v.20, n.1, p.129 - 135, 1996.

CRESTANA, M.S.M.; TOLEDO FILHO, D.V.; CAMPOS, J.B. Florestas: sistemas de recuperação com essências nativas. Campinas: Coordenadoria de Assistência Técnica Integral, 1993. 60p.

EASH, D. A. A. Geographic information system procedure to quantify drainage-basin characteristic. Water Resources Bulletin, v. 30 p. 1-8, 1994.

EASTMAN, J. R. Guide to Gis and image processing: IDRISI, 32. Wocester, USA: Clark University, 1999.

ESRI - Environmental Systems Research Institute, Inc. ArcGIS Professional GIS for the desktop, versão 8.2. CA. 2002.

FOODY, G. M. On the compensation for chance agreement in image classification accuracy assessment. Photogrametric Engineering and Remote Sensing. Bethesda, v. 58, n. 10, p. 1459-1460, 1992.

GARBRECHT J.; MARTZ, L. W. Digital elevation model issues in water resources modeling. In: ANNUAL ESRI USERS CONFERENCE, 1999.

GARBRECHT J. ; MARTZ, L. W. Network and subwatershed parameters extracted from digital elevation models: the bills creek experience. Water Resources Bulletin, v. 29, p.909-916, 1993.

GARCIA M. J. L.; CAMARASA, A. M. Use of geomorphological units to improve drainage network extraction from DEM: Comparision between automated extraction and photointerpretation methods in the Carraixet catchment (Valencia, Spain). JAG, n.3-4, p. 187-194, 1999.

IBGE - Instituto Brasileiro de Geografia e Estatística. Cartas topográficas: Anutiba, Divino São Lourenço, Guaçuí e Muqui. 1977. Escala 1:50.000.

MOURA, A. C. M. Globalização e metodologia no uso do geoprocessamento: estudo de casos de diferentes abordagens de análises espaciais. In: CONGRESSO BRASILEIRO DE CARTOGRAFIA, 18., 1997, Rio de Janeiro, RJ. Anais...Rio de Janeiro, 1997.

OLIVEIRA, M. J. Proposta metodológica para delimitação automática de Áreas de Preservação Permanente em topos de morro e em linha de cumeada. 2002. 53p. Dissertação (Mestrado em Ciência Florestal) - Universidade Federal de Viçosa, Vicosa, 2002.

PESSOA, M. C. P. Y; LUCHIARI, A. J.; FERNANDES, E. N.; LIMA, M. A. Principais modelos matemáticos e simuladores utilizados para análise de impactos ambientais das atividades agrícolas. Jaguariúna, EMBRAPA/CNPMA, 1997. 83p. (EMBRAPA, CNPMA. Documentos, 8)

RIBEIRO, C. A. A. S.; OlIVEIRA, M. J.; SOARES, V. P.; PINTO, F. A. C., Delimitação automática de áreas de preservação permanente em topos de morros e em linhas de cumeada: metodologia e estudo de caso. In: SEMINÁRIO DE ATUALIZAÇÃO EM SENSORIAMENTO REMOTO E SISTEMAS DE INFORMAÇÕES GEOGRÁFICAS APLICADAS À ENGENHARIA FLORESTAL, 5., 2002. Curitiba, PR. Anais...Curitiba, 2002. 7-18p.

ROSENFIELD, G. H.; FITZPATRICK-LINS, K. A coefficient of agreement as a measure of thematic classification 
accuracy. Photogrammetric Engineering and Remote Sensing, v. 52, n. 2, p. 223-227, 1986.

SOARES, V. P.; MOREIRA, A. A.; RIBEIRO, J. C.; RIBEIRO, C. A. A. S.; SILVA, E. Avaliação das áreas de uso indevido da terra em uma micro-bacia no município de Viçosa, MG, através de fotografias aéreas e Sistemas de Informação Geográfica. Revista Árvore, v. 26, n. 2, p. 243-251, 2002.

STURM, S.; ANTUNES, A. F.; LINGNAU, C.; BAHR, H. P. Análise da ocupação em Áreas de Preservação Permanente (APP) na área urbana do município de Matinhos utilizando a imagem Ikonos II. In: COLÓQUIO BRASILEIRO DE CIÊNCIAS GEODÉSICAS, 3., 2003. Disponível em: <www.definiensimaging.com/documents/publications/uli.pdf>. Acesso em: 19 jan. 2004.

TOWSHEND, J. R. G. Environmental database and GIS. In: MAGUIRE, D.J., GOODCHILD, M.F., 14. RHIND, D.W. Geographical information systems : principles and applications. New York : Longman Scientific \& Technical, 1992. p., p. 201-205.

TRIBE, A. Automated recognition of valley lines and drainage networks from grid digital elevation models: a review and a new method. Journal of Hidrology, v. 139, p. 263-293, 1992.

XAVIER DA SILVA. Geoprocessamento e análise ambiental. Revista Brasileira de Geografia. v. 54, p. 47-61, 1992. 